\title{
Datos de base de la vega del Guadalquivir
}

La información de carácter patrimonial contenida en el Sistema de Información para la Gestión Integral del Patrimonio Cultural, relativa a la vega del Guadalquivir, se analizará en base al patrimonio inmueble que se haya localizado cartográficamente en la misma.

Esta zona comprende términos municipales incompletos pertenecientes a las provincias de Córdoba, Jaén y Sevilla. Los términos municipales afectados son los siguientes: en la provincia de Córdoba: Adamúz, Almodovar del Río, El Carpio, Córdoba, Fuente Palmera, Hornachuelos, Montoro, Palma del Río, Pedro Abad, Posadas, Villa del Río y Villafranca de Córdoba. Todos ellos incompletos menos Palma del Río. En la provincia de Jaén: Andújar, Espelúy, Lopera, Marmolejo y Villanueva de la Reina. Todos incompletos menos Espelúy. En la provincia de Sevilla: Alcolea del Río, Brenes, Cantillana, Carmona; Écija, Lora del Río, Peñaflor, Tocina, Villanueva del Río y Minas y Villaverde del Río. Todos ellos incompletos menos Bre- nes y Tocina. Se han localizado 937 inmuebles; 503 en Córdoba, 179 en Jaén y 255 en Sevilla.

De estos inmuebles el 90\% corresponden a sitios arqueológicos, debido a que ya desde el Paleolítico comienzan a localizarse asentamientos junto a las márgenes del río, aunque es en Época romana cuando se observa la mayor cantidad de sitios. La gran fertilidad del suelo de la vega, traerá como consecuencia la explotación agrícola y una gran producción de vino, aceite y cereales que se exportan a Roma y otras zonas del Imperio, lo que explica la gran cantidad de villae y alfares romanos que se encuentran en este territorio. Entre los sitios arqueológicos mas destacados de la vega están el Llanete de los Moros, Celti, Cercadilla o Madinat Al -Zahara.

En cuanto al patrimonio arquitectónico, la mayor cantidad de inmuebles localizados corresponden a Córdoba, especialmente a su centro histórico que contiene gran cantidad de inmuebles protegidos.
Entre estos inmuebles destacan un gran número de iglesias y palacios como el Palacio de Viana, la Iglesia de Regina o los puentes sobre el río en toda la vega.

El patrimonio etnológico se ve reflejado en la vega a través de cortijos, haciendas, alfares y molinos, ya que en la época actual se continúa con la actividad agropecuaria y de transformación en la zona.

Desde el punto de vista de las tipologias funcionales y periodos históricos a los que se asocia el patrimonio inmueble de la zona se han utilizado los términos del Tesauro de Patrimonio Histórico agrupándolos de la siguiente manera, ya sea patrimonio arqueológico, arquitectónico o etnológico:

- Edificaciones productivas que contienen las siguientes tipologías: edificios industriales, agropecuarios, ganaderos, complejos extractivos, comerciales, de hosteleria, almacenes, minas y locales comerciales. Los inmuebles pertenecientes a esta tipología suponen un $37 \%$ del total.
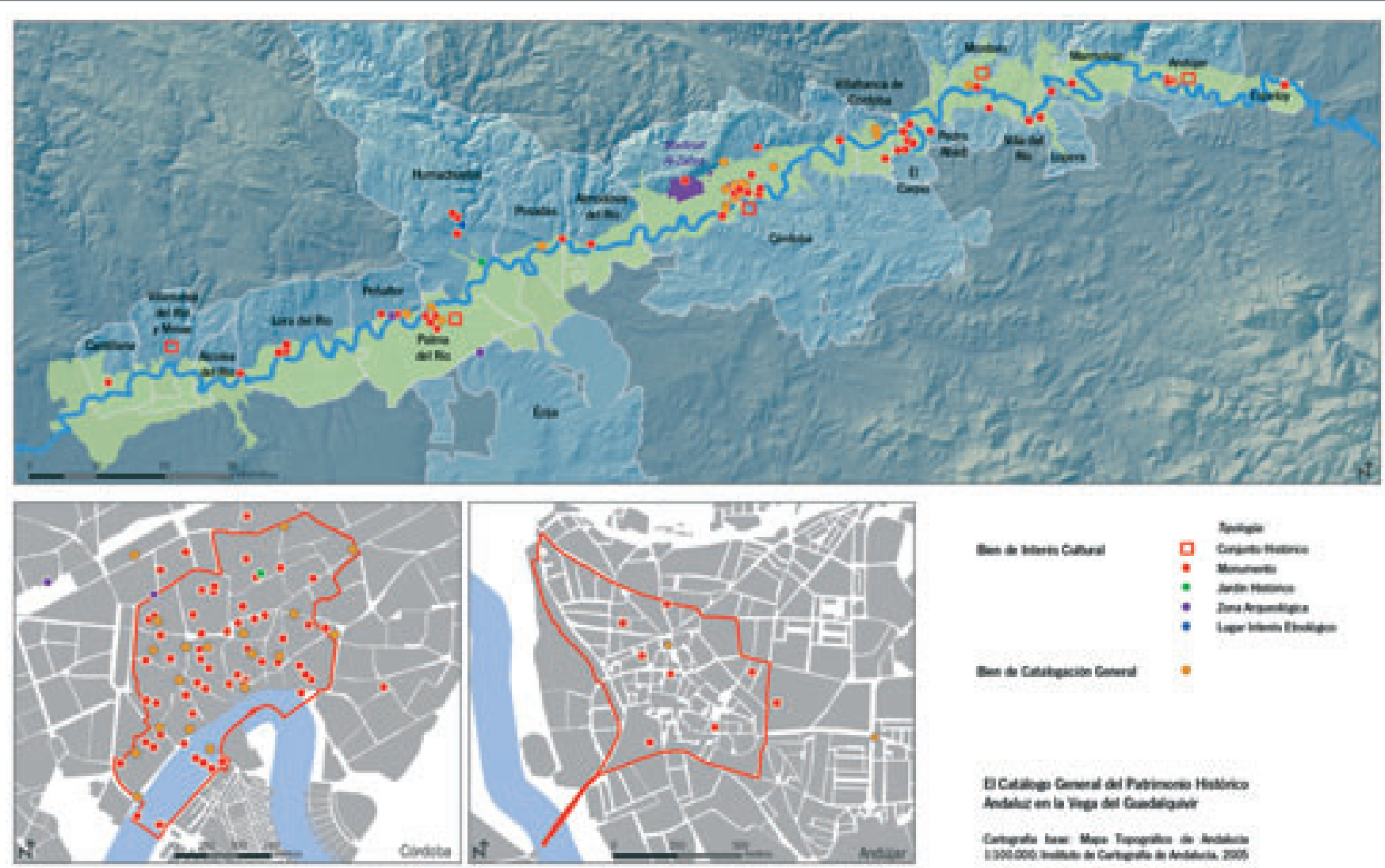

Catálogo General de Patrimonio Histórico Andaluz

La Ley 14/2007 de 26 de noviembre, de Patrimonio Catalogación General y los incluidos en el Inventario Histórico de Andalucia concibe el Catálogo General General de Bienes Muebles del Patrimonio Histórico del Patrimonio Histórico Andaluz, como instrumento Español.

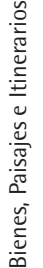
fundamental para la tutela y conocimiento de los bienes en él inscritos. El Catálogo, según el artículo 7, punto 1 de esta Ley, comprende tres categorías de bienes, los Bienes de Interés Cultural, los bienes de
En el plano de la demarcación de la vega del Guadalquivir, hemos localizado un total de 153 inmuebles protegidos, de los cuales 120 son Bienes de Interés Cultural y 33 son de Catalogación General.

Alfonso Montejo Ráez, Olga Viñuales Meléndez Servicio de Protección del Patrimonio Histórico Dirección General de Bienes Culturales 


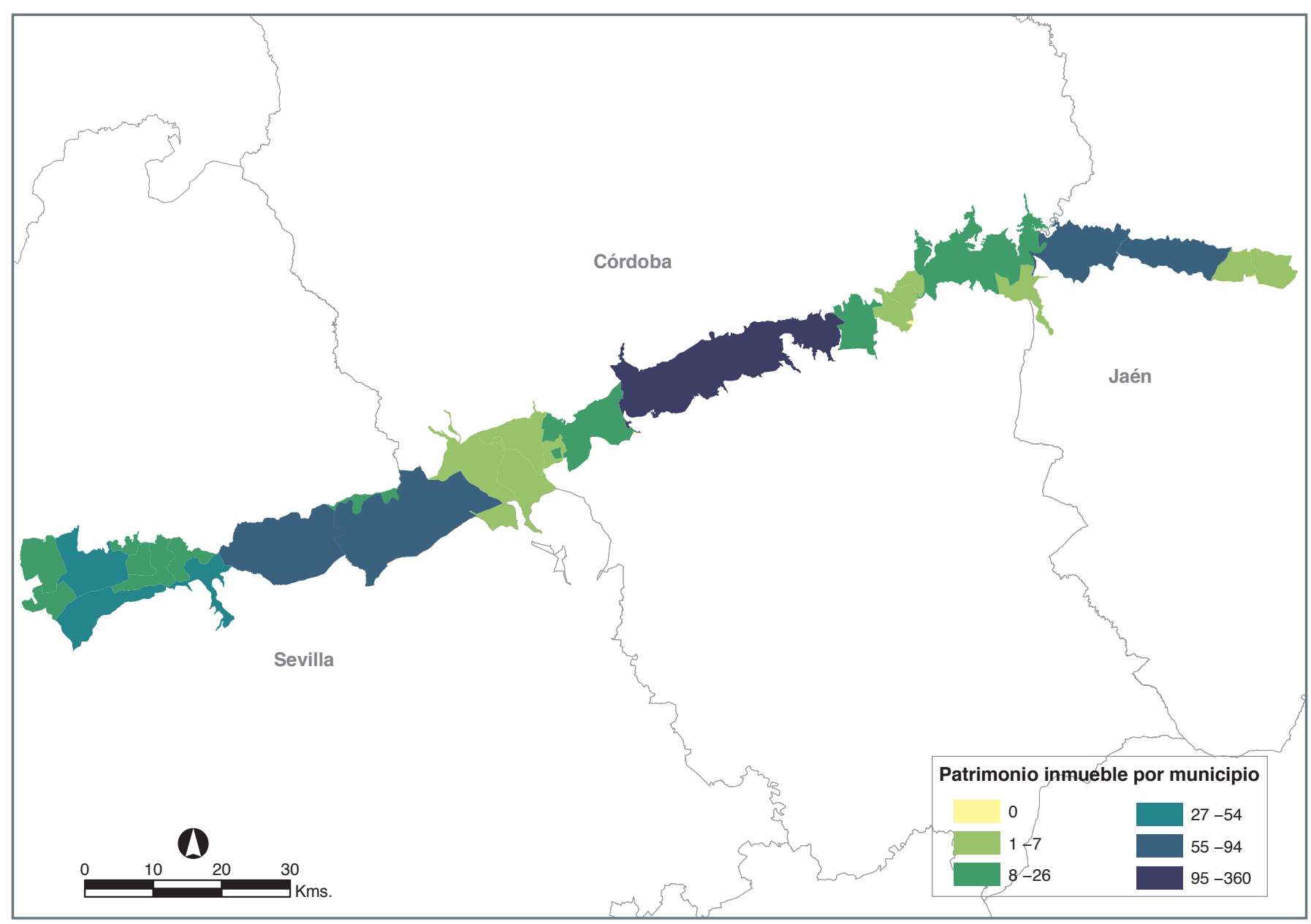

Tipologías Funcionales

Periodos Históricos
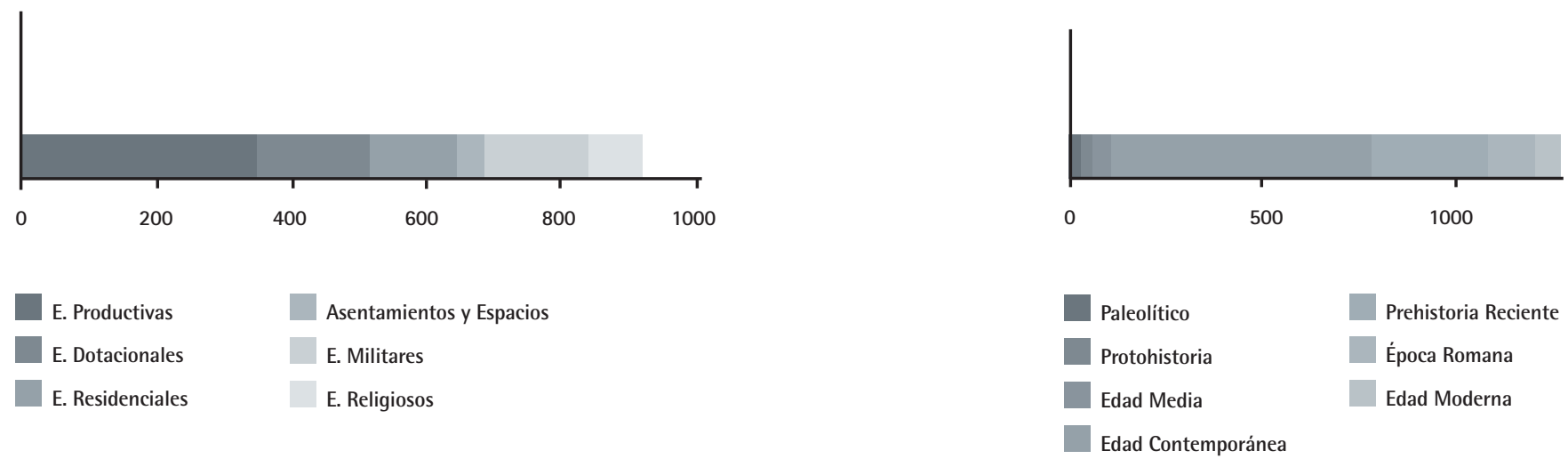

- Edificaciones dotacionales que engloban las siguientes tipologías: edificios administrativos, asistenciales, de comunicación, de espectáculo, de exposiciones, de transporte, baños públicos y depósitos documentales. Los inmuebles pertenecientes a esta tipología suponen un $14 \%$ del total.

- Espacios libres que agrupan: asentamientos, espacios rurales, espacios urbanos y zonas verdes. Los inmuebles pertenecientes a esta tipología suponen un $20 \%$ del total.

- Edificaciones militares que abarcan: fortificaciones y torres defensivas Las entidades pertenecientes a esta tipología suponen un $4 \%$ del total.
- Edificaciones religiosas. Los inmuebles pertenecientes a esta tipología suponen un $8 \%$ del total.

- Edificaciones residenciales que comprenden: viviendas, casas y palacios. Los inmuebles pertenecientes a esta tipología suponen un 17\% del total.

Esta distribución tipológica parece bastante equilibrada, siendo mayoritarios los edificios productivos y los asentamientos que suponen entre ambos un 57\% del total. Les siguen los edificios dotacionales y después los residenciales y los religiosos, siendo los últimos los militares. Ello se debe como ya hemos dicho a que el patrimonio arqueológico cuenta con más del doble de inmuebles registrados que las otras dos caracterizaciones juntas, por lo que sus tipologias marcan la pauta general.

En cuanto a los periodos históricos, el que más destaca es la Época Romana, con 671 entidades patrimoniales, con una cantidad intermedia tenemos la Edad Media con 299 inmuebles y los que menos contienen son la Edad Contemporánea con 57 y la Prehistoria Reciente con 25.

Pilar Mondéjar Fernández de Quincoces Salud Soro Cañas

Centro de Documentación y Estudios del IAPH 


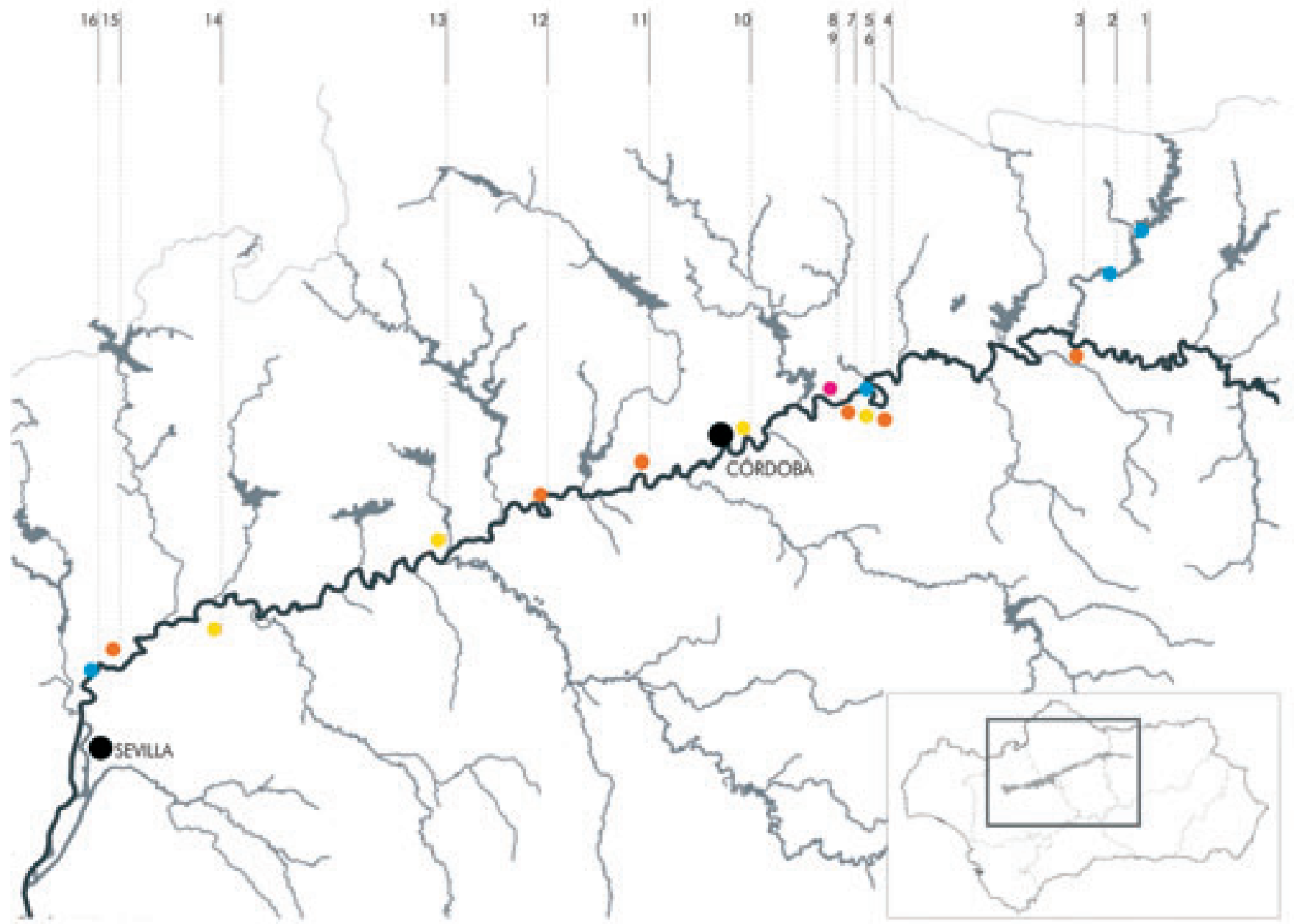

政

- 1 Presa y central del Jándula (1927)

- 2 Presa y central de Encinarejo (1928)

- 3 Pueblo de colonización de Llanos del Sotillo (1956)

- 4 Pueblo de colonización de Maruanas (1964)

- 5 Presa y central de El Carpio (1925)

- 6 Silo de almacenamiento de la fábrica de Pastas Gallo

- 7 Pueblo de colonización de San Antonio (1960)

- 8 Escuela Nacional de niñas (1933)
- 9 Escuela Nacional de niños (1928)

- 10 Fábrica de cervezas "El Águila" (1962)

- 11 Pueblo de colonización de Encinarejo (1942)

- 12 Pueblo de colonización de Rivero de Posadas (1953)

- 13 Fábrica de harinas y tejidos de yute Sánchez Pastor (1926)

- 14 Fábrica azucarera San Fernando y destilería Los Rosales (1925)

- 15 Pueblo de Colonización de Esquivel (1952-1955)

- 16 Presa y central de Alcalá del Río (1928) 